HEALTH PSYCHOLOGY REPORT · VOLUME 10(2), 2022 ORIGINAL ARTICLE
Lam Q. Truong (D)
$1 \cdot \mathrm{A}, \mathrm{B}, \mathrm{C}, \mathrm{D}, \mathrm{E}, \mathrm{F}, \mathrm{G}$
Thuy B. Luong (D)
$1 \cdot \mathrm{A}, \mathrm{B}, \mathrm{D}, \mathrm{E}, \mathrm{G}$
Thu H. Tran (D)

$1 \cdot \mathrm{A}, \mathrm{D}, \mathrm{E}, \mathrm{F}$

Ngan H. Dang
Lien H. Nguyen $\mathbb{D}$
$1 \cdot$ A,D,E,F
Trang T. Nguyen (DD
$1 \cdot$ A,C,D,E

Phuong T. H. Nguyen (D)

$3 \cdot \mathrm{B}, \mathrm{D}, \mathrm{E}$

\title{
Infertility-related stress, social support, and coping of women experiencing infertility in Vietnam
}

BACKGROUND

Women with an infertility problem living in traditional and developing countries face extensive social pressure, infertility-related stress, and distress, which possibly affect their choices of coping strategies. The present study aims to investigate the impact of infertility-related stress and social support on coping of Vietnamese women who live with an infertility diagnosis.

\section{PARTICIPANTS AND PROCEDURE}

A cross-sectional study was conducted with 192 women diagnosed with infertility at two hospitals in the north and central regions of Vietnam. Participants completed a questionnaire consisting of the Multidimensional Scale of Perceived Social Support, the Copenhagen Multi-centre Psychosocial Infertility coping scales and the Fertility Problem Inventory, and questions about their sociodemographic characteristics, infertility-related history, and key social relationships. Four linear regression analyses were performed on four coping strategies: active-avoidance coping (AAC), active-confronting coping (ACC), passive-avoidance coping (PAC), and meaning-based coping (MBC).
RESULTS

The findings show that high infertility-related stress significantly predicted the use of avoidance coping strategies (AAC and PAC) among these women, while those with a high level of perceived social support tended to use ACC and MBC. None of the four linear regression models support the moderating role of social support in the relationship between infertility-related stress and coping styles.

\section{CONCLUSIONS}

The study findings show that levels of infertility-related stress and perceived social support have a direct effect on the choice of coping strategies among Vietnamese women diagnosed with infertility. The study results have practical implications in the Vietnamese context, including: (i) the development and adaptation of evidence-based and culturally appropriate interventions and counselling strategies; and (ii) social policy advocacy to better support women diagnosed with infertility, their husbands, and both as couples.

\section{KEY WORDS}

social support; coping; Vietnam; infertility-related stress

ORGANIZATION - 1: VNU University of Social Sciences and Humanities - Vietnam National University, Hanoi, Vietnam . 2: Independent psychologist, Vietnam · 3: University of Science and Education - The University of Danang, Danang, Vietnam

AUthors' COntributions - A: Study design - B: Data collection - C: Statistical analysis - D: Data interpretation .

E: Manuscript preparation · F: Literature search · G: Funds collection

Corresponding AUthor - Lam Q. Truong, Ph.D., Faculty of Psychology, University of Social Sciences and Humanities -

Vietnam National University, 336 Nguyen Trai, Thanh Xuan District, 10000 Hanoi, Vietnam,

e-mail: lamtq.psy@gmail.com

to Cite this ARTICle - Truong, L. Q., Luong, T. B., Tran, T. H., Dang, N. H., Nguyen, L. H., Nguyen, T. T., \& Nguyen, P. T. H.

(2022). Infertility-related stress, social support, and coping of women experiencing infertility in Vietnam. Health

Psychology Report, 10(2), 129-138. https://doi.org/10.5114/hpr.2022.113437

RECEIVED 23.06.2021 · REVIEWED 10.11.2021 · ACCEPTED 16.01.2022 • PUBLISHED 22.02.2022 


\section{BACKGROUND}

\section{OVERVIEW OF WOMEN WITH INFERTILITY}

Infertility has been considered a major reproductive health problem worldwide. The International Committee for Monitoring Assisted Reproductive Technology (ICMART) and the World Health Organization (WHO) define infertility as a reproductive related disease which causes the failure to achieve a clinical pregnancy after 12 months or more among couples with regular unprotected sexual intercourse (Zegers-Hochschild et al., 2009). In 2010, there were approximately 48.5 million couples diagnosed with infertility (Mascarenhas et al., 2012). The WHO (2012) indicated that the overall burden of infertility on women remained the same from 1990 to 2010 across 190 countries.

Infertility and infertility treatment are associated with burdens and stress among couples, such as financial burdens, life goal changes, and reduced selfesteem (Burns \& Covington, 2006; Luckse \& Vacc, 1999). Newton et al. (1999) summarized five key aspects of infertility related stress, namely: social concern, sexual concern, relationship concern, rejection of childfree lifestyle, and need for parenthood. The importance of having children is particularly emphasized among couples, especially women in Asia and Africa, as it is associated with their worth in their family and community (Dyer \& Patel, 2012). In many Asian countries, such as China, having children, particularly sons, to perpetuate one's family lineage is viewed as a priority of a married couple (Lee et al., 2001; Loke et al., 2012). Therefore, those who cannot meet this social standard reported a high level of stress associated with the disdain from their own community (Lee \& Sun, 2000). For example, $80 \%$ of Chinese married couples with subfertility report their fear of infertility and an unpromising future without children in their family and community (Lau et al., 2008). In fact, subfertility and infertility are associated with marriage conflicts, divorce, abandonment, and financial insecurity (Patel, 2016).

Although infertility affects both husband and wife as a couple, women, especially women in Asian countries, tend to experience higher stress related to infertility, due to the common social prejudice that infertility is mostly women's problem (Chiew \& Jan, 2018; Lee et al., 2009; Van den Broeck et al., 2010). Chinese women explicitly show their worries about the attitude of their husbands' families. The worry level is even higher if their husbands are the oldest or the only son in the family (Lee \& Sun, 2000; Lee et al., 2009). The mental health problems related to infertility are higher among Iranian women even if the cause of infertility is male. The rates of depression, anxiety, hypochondriasis, and paranoia in infertile women and the wives of infertile men were significantly higher than those in husbands of infertile females in Iran (Karimzadeh et al., 2017). Women with infertility and/or infertility treatment list multiple difficulties related to their social relationships, career, financial, and health care. Depression has also been found to be very common in this group (Benyamini et al., 2005; Galhardo et al., 2020; Karimzadeh et al., 2017; Meller et al., 2002).

A high level of stress related to infertility requires a high level of coping effort among women with infertility problems (Schmidt et al., 2005a, b). Schmidt et al. (2005a, b) suggested four styles of coping among people with infertility: (1) active-avoidance coping (AAC), (2) active-confronting coping (ACC), (3) passive-avoidance coping (PAC), and (4) meaning-based coping $(\mathrm{MBC})$. Some other coping strategies among people with infertility problems are avoidance, blaming, responsibility-taking, problem-focused, positive re-evaluation, and social support seeking (Gourounti et al., 2010). Women tend to adopt avoidance coping strategies, i.e., avoiding thoughts, emotions, and situations reminding them of pregnancy and parenthood (Galhardo et al., 2020). Avoidance coping and confronting coping are both associated with a high level of stress among people with infertility problems (Lykeridou et al., 2011). In addition, women treated for infertility often struggle with coping with their own emotions, such as fear and worry, during their treatment (Podolska \& Bidzan, 2011).

Social support is considered one of the key protective factors for women suffering from infertilityrelated stress. It is also worth mentioning that women use more social support than their male partners (Cousineau \& Domar, 2007). Social support not only helps lower the level of infertility stress (Gibson \& Myers, 2002; Matsubayashi et al., 2004; Öztürk et al., 2021; Schmidt et al., 2005a, b), but it also reduces depression and anxiety among women (Dembińska, 2016; Lechner et al., 2007; Verhaak et al., 2005). On the other hand, lack of social support, particularly from husbands, is associated with women's negative emotions and dissatisfaction with marriage (Luk \& Loke, 2014). Although previous studies emphasize the importance of social support with respect to infertilityrelated stress among women, it remains unclear about whether social support affects the choice of coping styles, both as an independent factor and a moderator in the relationship between infertility-related stress and coping styles. In addition, it is important to investigate their relationship in a specific socio-historical context.

\section{WOMEN WITH INFERTILITY IN VIETNAM}

In the specific context of Vietnam, infertility has been a great concern to public health professionals. Approximately $7.7 \%$ of 14,300 couples aged from 15 to 
49 in eight regions in Vietnam were diagnosed with infertility (Ministry of Health, 2017). The sociocultural context in Vietnam places intensive pressure on women with infertility problem. In developing countries, children are perceived as a source of marriage connection and family cohesion, as well as a future labour and income source for a couple in their older age (Barden-O’Fallon, 2005; Hollos et al., 2009; Wiersema et al., 2006). A common folk saying, "More children, more wealth" (Nhiều con nhiều của), conveys this belief in Vietnamese culture. Relatives, friends, neighbours, and coworkers raise unintentional confronting questions to women if they do not have children after the first year of marriage (Nguyen, 2011a; Wiersema et al., 2006). The uncertainty of causes, possible solutions and results regarding the infertility problem and treatment increases the internal pressure on women. In addition, it is a common stigma in traditional societies that infertility is mainly women's dysfunction and accountability (Greil et al., 2010; Karaca \& Unsal, 2012; Miles et al., 2009), as another old saying stating "unblessed trees bear no fruits, unblessed women bear no children" (Cây độc không trái, gái độc không con) imposes much higher stress on Vietnamese women (Tran et al., 2020). Scholars share their findings on negative emotions that Vietnamese women diagnosed with infertility experience, such as deep sadness, guilt, loneliness, relationship and future insecurity (Wiersema et al., 2006), low spirit, pain, disappointment, self-pity (Nguyen, 2011a), anxiety, distress, and hopelessness (Nguyen \& Nguyen, 2017; Truong, 2020), and depression (Vo et al., 2019). Depression was detected in $12.2 \%$ of women diagnosed with infertility (Vo et al., 2019).

Faced with multiple challenges and negative emotions associated with infertility, Vietnamese women adopt different coping strategies. A few available studies on this group report different ways of women's coping. In Nguyen's study (2011b), women mostly adopted a direct confronting coping strategy by actively seeking treatment mainly from formal healthcare services. Some of them showed both a positive attitude and wishful thinking, while others sought help from religious facilities for this out-of-control problem. In another study conducted with Vietnamese women in the north, passive coping was found to be adopted more often than active coping. MBC was the least frequent use of coping, particularly in the group of older infertile women (aged 36-45). In addition, women in rural areas did not either show their emotions regarding infertility treatment or accept comforting words from others (Dang et al., 2020).

During the coping process, social support, including tangible, information, and emotion support, plays an important role. On the other hand, too much attention from family and in-laws and extensive suggestions on food and treatment methods could bring more pressure and stress than encouragement to women.
Such pressure and stress forced women to try to meet their families' expectations; hence, it could bring more psychological harm to them (Wiersema et al., 2006). However, this study and the others do not clarify the level of social support Vietnamese women received while coping with their infertility-related stress. In addition, not much is known about the underlying mechanism of the relationship among perceived social support, infertility-related stress, and the choice of coping strategies among Vietnamese women.

\section{RESEARCH AIMS AND QUESTIONS}

Considering the knowledge gaps in the literature, the present study aims to investigate the impact of infertility-related stress and social support on coping of Vietnamese women who live diagnosed with infertility. To be more specific, this study seeks to answer the following research questions:

1. Does infertility-related stress have a direct impact on each coping style (AAC, ACC, PAC, and MBC)?

2. Does social support have a direct impact on each coping style?

3. Is the impact of infertility-related stress on each coping style modified by social support?

\section{PARTICIPANTS AND PROCEDURE}

\section{PARTICIPANTS}

A total of 192 women with a primary infertility diagnosis, who had never become pregnant before, were recruited from two hospitals in the northern and central regions of Vietnam, using convenient sampling. The key demographic characteristics of participants are presented in Table 1. All women in the study, aged 22 and above, were married for at least a year. Their average years of pregnancy expectation were 4.76 $(S D=3.18)$, which was close to their average years of diagnosed infertility $(M=4.35, S D=3.10)$. Participants reported an average score of infertility-related stress of $164.20(S D=17.76)$, while social support averaged $61.57(S D=13.20)$. The mean scores of AAC, ACC, $\mathrm{PAC}$, and MBC were $8.12(S D=2.60), 19.94(S D=3.89)$, $9.32(S D=2.21)$, and $14.69(S D=2.47)$ respectively.

\section{MEASURES}

Infertility-related stress. Infertility-related stress in Vietnamese women was measured with the Fertility Problem Inventory (FPI; Newton et al., 1999). The FPI consists of 46 items covering five key aspects of infertility-related stress: (1) social concern (e.g., "It doesn't bother me when I'm asked questions about children"; "It doesn't bother me when others talk about their
Infertility-related stress, social support, and coping of women 
Table 1

Descriptive characteristics of the study sample $(N=192)$

\begin{tabular}{|c|c|c|c|c|}
\hline Variables & $\begin{array}{c}\text { Valid } \\
\text { observations }\end{array}$ & $\begin{array}{c}\%(n) \text { or } \\
{[\min -\max ]}\end{array}$ & $M(S D)$ & $\begin{array}{c}\text { Cronbach's } \\
\alpha \\
\end{array}$ \\
\hline \multicolumn{5}{|l|}{$\begin{array}{l}\text { Demographic characteristics/ } \\
\text { covariates }\end{array}$} \\
\hline Age & 182 & {$[22-45]$} & $31(4.50)$ & \\
\hline Education & 192 & & & \\
\hline High school and lower & & $39.58(76)$ & & \\
\hline College and higher & & $60.42(116)$ & & \\
\hline Years of marriage & 173 & {$[1-21]$} & $5.63(3.96)$ & \\
\hline Years of pregnancy expectation & 167 & {$[0.3-21]$} & $4.76(3.18)$ & \\
\hline Years of diagnosed infertility & 173 & {$[0.3-21]$} & $4.35(3.10)$ & \\
\hline \multicolumn{5}{|l|}{ Determinants } \\
\hline Infertility-related stress & 132 & {$[114-208]$} & $164.20(17.76)$ & .59 \\
\hline Social concern & 167 & [16-49] & $32.44(6.52)$ & .67 \\
\hline Sexual concern & 168 & {$[10-37]$} & $22.82(6.19)$ & .74 \\
\hline Relationship concern & 169 & {$[17-41]$} & $31.20(4.82)$ & .69 \\
\hline Rejection of child-free lifestyle & 157 & {$[16-48]$} & $33.43(6.67)$ & .80 \\
\hline Need for parenthood & 159 & {$[19-58]$} & $44.84(6.26)$ & .75 \\
\hline Social support & 175 & {$[12-84]$} & $61.57(13.20)$ & .90 \\
\hline \multicolumn{5}{|l|}{ Outcome variables } \\
\hline Active-avoidance coping (AAC) & 183 & {$[4-15]$} & $8.12(2.60)$ & .76 \\
\hline Active-confronting coping (ACC) & 174 & {$[9-28]$} & $19.04(3.89)$ & .77 \\
\hline Passive-avoidance coping (PAC) & 179 & [3-12] & $9.32(2.21)$ & .82 \\
\hline Meaning-based coping (MBC) & 177 & {$[9-20]$} & $14.69(2.47)$ & .57 \\
\hline
\end{tabular}

children"); (2) sexual concern (e.g., "I find I've lost enjoyment of sex because of the fertility problem"; "I feel like I've failed at sex"); (3) relationship concern (e.g., "I can't show my partner how I feel because it will make him/her feel upset"; "My partner doesn't understand the way the fertility problem affects me"); (4) rejection of childfree lifestyle (e.g., "Couples without a child are just as happy as those with children"; "I could see a number of advantages if we didn't have a child"); and (5) need for parenthood (e.g., "Pregnancy and childbirth are the two most important events in a couple's relationship"; "For me, being a parent is a more important goal than having a satisfying career"). For each item, participants chose one response out of six choices (1 - strongly agree; 2 - moderately agree; 3 - slightly agree; 4 - slightly disagree; 5 - moderately disagree; 6 - strongly disagree). Global stress was computed by summarizing the points of all 46 items. Cronbach's $\alpha$ coefficients of the five sub- scales were $.67, .74, .69, .79$, and .74 respectively, and of the global stress was .59.

Social support. The Multidimensional Scale of Perceived Social Support (MSPSS, Zimet et al., 1988) was used to measure the level of perceived social support from family (e.g., "My family really tries to help me"); friends (e.g., "I can talk about my problems with my friends"); and significant others, who were not family and friends (e.g., "There is a special person with whom I can share my joys and sorrows"). Twelve-item ratings were set on a 7-point Likert-type scale ranging from 1 (very strongly disagree) to 7 (very strongly agree). Cronbach's $\alpha$ coefficient of this variable was .90 .

Coping. We adopted the Copenhagen Multi-Centre Psychosocial Infertility (COMPI; Schmidt et al., $2005 a, b)$ scale to measure different styles of coping of Vietnamese women. COMPI includes four sub-scales, namely: (1) active-avoidance coping (AAC) (e.g., "I leave when people are talking about pregnancies 
and children"), (2) active-confronting coping (ACC) (e.g., "I ask other childless people for advice"), (3) passive-avoidance coping (PAC) (e.g., "I hope a miracle will happen"), and (4) meaning-based coping (MBC) (e.g., "I think about the fertility problem in a positive light"). Participants chose one response ranging from 1 to 4 for each item (1 - not used; 2 - used somewhat; 3 - used quiet a bit; and 4 - used a great deal). The score of each sub-scale was the summation of its items' points. Cronbach's $\alpha$ coefficients of the four subscales were $.75, .76, .82$, and .56 respectively.

Background variables. A set of background variables was included in the study, consisting of a binary variable (education with 0 - high school and lower, 1 - college and higher), and continuous variables (age, years of marriage, years of pregnancy expectation, and years of diagnosed infertility).

\section{PROCEDURE}

The study was approved by the Committee for appraisal and issuance of research ethics codes of University of Social Sciences and Humanities, Vietnam National University in Hanoi (no. 2890/CN-XHNV$\mathrm{KH}$ ). Data collection consisted of two phases. In phase 1 , the standardized scales in the questionnaire were translated from English to Vietnamese by the core research team. Then, an independent consultant conducted a back translation from Vietnamese to English to validate the translation. A pilot study with 55 infertile women in Northern Vietnam was conducted to test the cultural appropriateness and feasibility of the questionnaire, as well as to finetune it. A professional team provided feedback for the revised questionnaire before finalizing it for phase 2 .

In phase 2, the research team collaborated with the health professionals at the two hospitals to invite women with a primary infertility diagnosis to participate in the study. We explained the study aim and procedure, and potential benefits and risks when participating in the study. We also made it clear that participants could participate in and withdraw from the study voluntarily at any time without any consequences. Their information would be used for research purposes only and would remain anonymous and protected in the study. For the 192 women who agreed to participate in the study (none of them dropped out), trained research assistants interviewed them using the finalized questionnaire at the hospital. Each interview took from 30 to 35 minutes and participants received a gift bag of supplements.

\section{DATA ANALYSIS}

First, descriptive and correlation analyses were conducted on key variables of the study. Second, four linear regression analyses were performed on four outcome variables (AAC, ACC, PAC, and MBC). The background variables (age, education, years of marriage, years of pregnancy expectation, and years of diagnosed infertility) and determinants (infertilityrelated stress and social support) were entered in the four models. Interactions between the two determinants for each outcome variable were also performed. Data were analysed using STATA 16.0 and the statistical significance level was set at .05 .

\section{RESULTS}

\section{BIVARIATE CORRELATIONS AMONG STUDY VARIABLES}

Table 2 presents bivariate correlations among key variables of the study. Being older and having higher infertility-related stress were associated with higher use of AAC $(r=-.22, p=.003$ and $r=.45, p<.001)$ and PAC $(r=-.18, p=.017$ and $r=.30, p<.001)$, while having more social support was associated with higher use of ACC $(r=.39, p<.001)$, and MBC $(r=.44, p<.001)$, and PAC $(r=.16, p=.042)$. Among the four styles of coping, ACC, PAC, and MBC were significantly correlated with each other, while AAC was associated with ACC and PAC only.

\section{MULTIVARIATE MODELS OF COPING}

Table 3 summarizes multivariate models of the use of four coping styles. In Models 1 and 3, after controlling for background variables, infertility-related stress was found to have a significant, direct effect on the use AAC $(\beta=.41)$ and PAC $(\beta=.32)$. In Models 2 and 4, social support was a significant predictor of the use of ACC $(\beta=.37)$ and MBC $(\beta=.46)$. In Model 1 only, background variables, including age $(\beta=-.34)$ and years of pregnancy expectation $(\beta=-.46)$, were found to significantly predict the use of coping (AAC). In each model, neither infertilityrelated stress nor social support showed a direct effect on the style of coping; therefore, none of the four models met the requirements to perform interaction analyses between these two determinants. In other words, no interactions were found between infertility-related stress and social support in all four models.

\section{DISCUSSION}

The present study examines the relationship among infertility-related stress, social support, and coping of 192 Vietnamese women diagnosed with infertility in the north and central regions. The findings show that high infertility-related stress significantly predicted
Infertility-related stress, social support, and coping of women 
the use of avoidance coping strategies (AAC and PAC) among these women, while those with a high level of perceived social support tended to use ACC and MBC. None of the four linear regression models show the moderating role of social support in the relationship between infertility-related stress and coping styles. This study, however, has its limitations. Data were collected with a small sample of 192 women

\section{Table 2}

Correlation of studied variables

Lam Q. Truong, Thuy B. Luong, Thu H. Tran, Ngan H. Dang, Lien H. Nguyen, Trang T. Nguyen, Phuong T. H. Nguyen

Correlation of studied variables

(1)

(2) (3)

(4) (5)

(6) (7)

(8)

(9)

(10) (11)
(1) AAC

$-$
(2) ACC

$.34^{*} \quad-$
(3) PAC
$.23^{*} .35^{*} \quad-$
(4) MBC
$.07 \quad .39^{*} \quad .33^{*} \quad-$
(5) Age
$\begin{array}{llll}-.22^{*} & -.01 & -.18^{*} & -.12\end{array}$
(6) Education
$\begin{array}{llllll}-.14 & -.15 & -.10 & -.05 & .02 & -\end{array}$
(7) Years of marriage
$\begin{array}{lllllll}-.01 & .0 & -.06 & -.09 & .61^{*}-.19^{*} \quad-\end{array}$
(8) Years of pregnancy $\begin{array}{llllllll}-.06 & -.01 & -.05 & -.15 & .49^{*} & -.19^{*} & .83^{*}\end{array}$ expectation
(9) Years of diagnosed $\quad \begin{array}{lllllllllll}-.02 & .04 & -.03 & -.11 & .47^{*} & -.19^{*} & .77^{*} & .93^{*} & -\end{array}$ infertility
(10) Infertility-related $\quad .45^{*} \quad \begin{array}{llllllllll} & .15 & .30^{*} & -.09 & -.14 & -.34^{*} & .01 & .00 & -.04 & -\end{array}$ stress

(11) Social support

$\begin{array}{lllllllllll}.06 & .39^{*} & .16^{*} & .44^{*} & .08 & -.13 & .05 & .04 & .07 & -.001 & -\end{array}$

Note. AAC - active-avoidance coping; ACC - active-confronting coping; PAC - passive-avoidance coping; MBC - meaning-based coping; ${ }^{*} p<.05$.

Table 3

Linear regression models of coping

\begin{tabular}{|c|c|c|c|c|}
\hline & \multicolumn{4}{|c|}{ Standardized coefficient $(\beta)$} \\
\hline & Model 1 (AAC) & Model 2 (ACC) & Model 3 (PAC) & Model 4 (MBC) \\
\hline \multicolumn{5}{|l|}{ Background variable } \\
\hline Age & $-.34^{*}$ & .17 & .02 & .06 \\
\hline Education (college and higher) & .00 & -.18 & -.14 & -.07 \\
\hline Years of marriage & .26 & -.11 & -.12 & -.21 \\
\hline Years of pregnancy expectation & $-.46^{*}$ & -.01 & -.08 & -.23 \\
\hline Years of diagnosed infertility & .39 & -.08 & .12 & .18 \\
\hline \multicolumn{5}{|l|}{ Determinant } \\
\hline Infertility-related stress & $.41^{*}$ & .10 & $.32^{*}$ & -.06 \\
\hline Social support & -.001 & $.37^{*}$ & .17 & $.46^{*}$ \\
\hline \multicolumn{5}{|l|}{ Summary statistic } \\
\hline$R^{2}$ & $.31^{*}$ & $.19^{*}$ & $.18^{*}$ & $.26^{*}$ \\
\hline Adjusted $R^{2}$ & $.26^{*}$ & $.13^{*}$ & $.12^{*}$ & $.20^{*}$ \\
\hline
\end{tabular}

Note. AAC - active-avoidance coping; ACC - active-confronting coping; PAC - passive-avoidance coping; MBC - meaning-based coping; ${ }^{*} p<.05$. 
diagnosed with infertility using the convenient sampling method, which restricts the generalizability of the study results. Due to the small sample size, the study could not detect the effect of the geographical and cultural context on coping styles of participating women. Despite these limitations, the study results provide an insight into the coping mechanism of this vulnerable and hard-to-reach group in the Confucianism society of Vietnam.

Consistent with the literature on infertile women in different contexts (Peterson et al., 2006a, cited in Peterson et al., 2008; Schmidt et al., 2005a; Terry \& Hynes, 1998), infertility-related stress was found to be significantly associated with avoidance coping strategies, including both AAC and PAC, among Vietnamese women diagnosed with infertility. Under intensive pressure to have children in a traditional society, where becoming a mother is not seen as a private matter, women often face questions about their pregnancy. Especially, young people living with their parents after getting married, and having at least one son for the succession of the family name, are considered criteria of filial piety (Ha et al., 2020). These situations often bring them emotional pain, as well as increasing infertility-related stress and psychological distress (Greil et al., 2010; Peterson et al., 2008). Women with high infertility-related stress, hence, tend to protect themselves from painful experiences by adopting avoidance coping strategies (i.e., steering away or abandoning conversations related to pregnancy and motherhood) (Schmidt et al., 2005a). These strategies, however, were found to be linked to a rising level of infertility-related stress (Martins et al., 2011; Peterson et al., 2008).

In addition, our study results indicate that being older and expecting to be pregnant for a long time significantly predict the use of AAC among infertile Vietnamese women. In other words, the older they became and the longer they expected to be a mother, the more often these women avoided engaging in conversations related to pregnancy and motherhood with others. This finding could be explained by the wellknown information about the association between women's age and their chances of getting pregnant (Chandra et al., 2005; Cousineau \& Domar, 2007; Roupa et al., 2009; the Practice Committee of the American Society for Reproductive Medicine, 2006), which places more pressure on older women. They tend to adopt AAC as a way to protect themselves from added stress and painful feeling (Rashidi et al., 2011).

In line with previous studies (Crockett et al., 2007; Hayden et al., 2007; Peterson et al., 2008), our findings show that women with high levels of perceived social support tended to use ACC and MBC. Receiving adequate social support, such as useful information, financial aid, and sympathy, from family, friends, and others boosts women's sense of belonging and being respected (Rashidi et al., 2011; Thoits, 1995), and self-confidence to share their concerns and feelings, confront their problems, and actively participate in problem-solving (Crockett et al., 2007; Hayden et al., 2007). For example, they approach their infertility diagnosis with a positive attitude and actively search for a solution, such as asking other women with similar problems for advice and finding a meaning in their treatment process.

Notably, our study did not detect any significant interaction between infertility-related stress and social support in their relationships with coping styles in all four models. This could be explained by the fact that women often receive from social support from people without an infertility problem. Support from those sources could be counterproductive for women who live with infertility-related stress on daily basis, as they might think that others could not understand their experiences (Rashidi et al., 2011). In fact, infertile women tend not to seek help from their family members and friends (Pedro, 2015). On the other hand, although our study did not support the moderating effect of social support on the relationship between infertility-related stress and coping styles, this result should be reassessed in future studies with larger sample sizes.

\section{CONCLUSION AND IMPLICATIONS}

In summary, the study findings show that levels of infertility-related stress and perceived social support have a direct effect on the choice of coping strategies among Vietnamese women diagnosed with infertility. Future related studies could further examine the relationship among infertility-related stress, social support, and coping strategies in larger samples of women in different contexts and possibly with married men clinically diagnosed with infertility.

The study results have practical implications in the Vietnamese context. First, the key findings inform social service professionals about the importance of levels of infertility-related stress and perceived social support for women's choice of coping strategies, which is helpful to develop and adapt interventions and counselling strategies for not only women, but also for their husbands, and for both as couples. Second, our study results are evidence for social policy advocacy to better support women diagnosed with infertility in particular, and people, including both men and women, with this reproductive health problem in general.

\section{FUNDING SOURCE}

The research was funded by Vietnam National Foundation for Science and Technology Development (NAFOSTED) under grant number 501.01-2019.03.
Infertility-related stress, social support, and coping of women 


\section{REFERENCES}

Barden-O'Fallon, J. (2005). Unmet fertility expectations and the perception of fertility problems in a Malawian village. African Journal of Reproductive Health, 9, 14-25. https://doi.org/10.2307/3583459

Benyamini, Y., Gozlan, M., \& Kokia, E. (2005). Variability in the difficulties experienced by women undergoing infertility treatments. Fertility and Sterility, 83, 275-283. https://doi.org/10.1016/j.fertnstert. 2004.10.014

Lam Q. Truong,

Thuy B. Luong, Thu H. Tran, Ngan H. Dang, Lien H. Nguyen, Trang T. Nguyen, Phuong T. H. Nguyen

Burns, L. H., \& Covington, S. N. (2006). Psychology of infertility. In S. N. Covington \& L. H. Burns (Eds.), Infertility counseling: a comprehensive handbook for clinicians (pp. 1-19). Cambridge University Press.

Cousineau, T. M., \& Domar, A. D. (2007). Psychological impact of infertility. Best Practice \& Research Clinical Obstetrics \& Gynaecology, 21, 293-308. https:// doi.org/10.1016/j.bpobgyn.2006.12.003

Chiew, P. W., \& Jan, J. M. (2018). In vitro fertilisation: Women's questions and concerns in a Malaysian online forum. Pertanika Journal of Social Sciences \& Humanities, 26, 79-96.

Crockett, L. J., Iturbide, M. I., Torres Stone, R. A., McGinley, M., Raffaelli, M., \& Carlo, G. (2007). Acculturative stress, social support, and coping: Relations to psychological adjustment among Mexican American college students. Cultural Diversity and Ethnic Minority Psychology, 13, 347-355. https:// doi.org/10.1037/1099-9809.13.4.347

Chandra, A., Martinez, G. M., Mosher, W. D., Abma, J. C., \& Jones, J. (2005). Fertility, family planning, and reproductive health of U.S. women: Data from the 2002 National Survey of Family Growth. Vital and Health Statistics, 23, 1-160.

Dang, H. N., Truong, Q. L., \& Luong, B. T. (2020). Coping with infertility. Journal of Psychology, Vietnam Academy of Social Sciences, 10, 43-61.

Dembińska, A. A. (2016). Psychological determinants of life satisfaction in women undergoing infertility treatment. Health Psychology Report, 2, 146-158. https://doi.org/10.5114/hpr.2016.56617

Dyer, S. J., \& Patel, M. (2012). The economic impact of infertility on women in developing countries a systematic review. Facts, Views and Vision in $\mathrm{Ob}$ Gyn, 4, 102-109.

Galhardo, A., Alves, J., Moura-Ramos, M., \& Cunha, M. (2020). Infertility-related stress and depressive symptoms - the role of experiential avoidance: a cross-sectional study. Journal of Reproductive and Infant Psychology, 38, 139-150. https://doi.org/10. 1080/02646838.2019.1612046

Gibson, D. M., \& Myers, J. E. (2002). The effect of social coping resources and growth-fostering relationships on infertility stress in women. Journal of Mental Health Counseling, 24, 68-80.

Gourounti, K., Anagnostopoulos, F., \& Vaslamatzis, G. (2010). Psychosocial predictors of infertility related stress: a review. Current Women's Health Reviews, 6, 318-331.https://doi.org/10.2174/157340410793362159

Greil, A. L., Slauson-Blevins, K., \& McQuillan, J. (2010). The experience of infertility: a review of recent literature. Sociology of Health \& Illness, 32, 140-162. https://doi.org/10.1111/j.1467-9566.2009.01213.x

Ha, T. T., Różycka-Tran, J., Jurek, P., Thu, T. H., \& Hao, L. V. (2020). Vietnamese version of the Dual Filial Piety Scale: Preliminary validation in a student sample. Health Psychology Report, 8, 263-272. https://doi.org/10.5114/hpr.2020.95409

Hayden, B. Y., Parikh, P. C., Deaner, R. O., \& Platt, M. L. (2007). Economic principles motivating social attention in humans. Proceedings of the Royal Society B: Biological Sciences, 274, 1751-1756. https:// doi.org/10.1098/rspb.2007.0368

Hollos, M., Larsen, U., Obono, O., \& Whitehouse, B. (2009). The problem of infertility in high fertility populations: Meanings, consequences and coping mechanisms in two Nigerian communities. Social Science \& Medicine, 68, 2061-2068. https://doi. org/10.1016/j.socscimed.2009.03.008

Karaca, A., \& Unsal, G. (2012). The effects of infertility on women's mental health and role of psychiatric nursing. Journal of Psychiatric Nursing, 3, 80-85. https://doi.org/10.5505/phd.2012.02486

Karimzadeh, M., Salsabili, N., Akbari Asbagh, F., Teymouri, R., Pourmand, G., \& Soleimanieh Naeini, T. (2017). Psychological disorders among Iranian infertile couples undergoing assisted reproductive technology (ART). Iranian Journal of Public Health, 46, 333-341.

Lau, J. T. F., Wang, Q., Cheng, Y., Kim, J. H., Yang, X., \& Yi, T. H. (2008). Infertility-related perceptions and responses and their associations with quality of life among rural Chinese infertile couples. Journal of Sex \& Marital Therapy, 34, 248-267. https:// doi.org/10.1080/00926230701866117

Lee, T. Y., \& Sun, G. H. (2000). Psychosocial response of Chinese infertile husbands and wives. Archives of Andrology, 45, 143-148. https://doi.org/10.1080/ 01485010050193913

Lee, T. Y., Sun, G. H., \& Chao, S. C. (2001). The effect of an infertility diagnosis on the distress, marital and sexual satisfaction between husbands and wives in Taiwan. Human Reproduction, 16, 1762-1767. https://doi.org/10.1093/humrep/16.8.1762

Lee, G. L., Hui Choi, W. H., Chan, C. H.Y., Chan, C. L. W., \& Ng, E. H. Y. (2009). Life after unsuccessful IVF treatment in an assisted reproduction unit: a qualitative analysis of gains through loss among Chinese persons in Hong Kong. Human Reproduction, 24, 1920-1929. https://doi.org/10.1093/humrep/dep091

Lechner, L., Bolman, C., \& van Dalen, A. (2007). Definite involuntary childlessness: Associations between coping, social support and psychological distress. Human Reproduction, 22, 288-294. https://doi.org/10.1093/humrep/del327 
Lykeridou, K., Gourounti, K., Sarantaki, A., Loutradis, D., Vaslamatzis, G., \& Deltsidou, A. (2011). Occupational social class, coping responses and infertility-related stress of women undergoing infertility treatment. Journal of Clinical Nursing, 20, 1971-1980. https://doi.org/10.1111/j.1365-2702.2011.03696.x

Loke, A. Y., Yu, P. L., \& Hayter, M. (2012). Experiences of sub-fertility among Chinese couples in Hong Kong: a qualitative study. Journal of Clinical Nursing, 21, 504-512. https://doi.org/10.1111/j.13652702.2010.03632.x

Luk, B. H. K., \& Loke, A. Y. (2014). The impact of infertility on the psychological well-being, marital relationships, sexual relationships, and quality of life of couples: a systematic review. Journal of Sex \& Marital Therapy, 41, 610-625. https://doi.org/10. 1080/0092623x.2014.958789

Lukse, M. P., \& Vacc, N. A. (1999). Grief, depression, and coping in women undergoing infertility treatment. Obstetrics \& Gynecology, 93, 245-251. https://doi.org/10.1016/s0029-7844(98)00432-3

Mascarenhas, M. N., Flaxman, S. R., Boerma, T., Vanderpoel, S., \& Stevens, G. A. (2012). National, regional, and global trends in infertility prevalence since 1990: a systematic analysis of 277 health surveys. PLoS Medicine, 9, e1001356. https://doi. org/10.1371/journal.pmed.1001356

Matsubayashi, H., Hosaka, T., Izumi, S., Suzuki, T., Kondo, A., \& Makino, T. (2004). Increased depression and anxiety in infertile Japanese women resulting from lack of husband's support and feelings of stress. General Hospital Psychiatry, 26, 398-404. https://doi.org/10.1016/j.genhosppsych.2004.05.002

Martins, M. V., Peterson, B. D., Almeida, V. M., \& Costa, M. E. (2011). Direct and indirect effects of perceived social support on women's infertility-related stress. Human Reproduction, 26, 2113-2121. https://doi.org/10.1093/humrep/der157

Meller,W., Burns, L. H., Crow, S., \& Grambsch, P. (2002). Major depression in unexplained infertility. Journal of Psychosomatic Obstetrics and Gynaecology, 23, 27-30. https://doi.org/10.3109/01674820209093412

Miles, L. M., Keitel, M., Jackson, M., Harris, A., \& Licciardi, F. (2009). Predictors of distress in women being treated for infertility. Journal of Reproductive and Infant Psychology, 27, 238-257. https://doi. org/10.1080/02646830802350880

Ministry of Health (2017). Infertility in Vietnam is increasing. Retrived from http://yhth.vn/benh-vosinh-tai-viet-nam-dang-gia-tang_d3451.aspx

Newton, C. R., Sherrard, W., \& Glavac, I. (1999). The fertility problem inventory: Measuring perceived infertility-related stress. Fertility and Sterility, 72, 54-62. https://doi.org/10.1016/s0015-0282(99)00164-8

Nguyen, D. H. N., \& Nguyen. D. H. G. (2017). Mental health care needs in infertile people (Case study at Department of Reproductive Support, A. Thai Nguyen Hospital). Proceedings of International
Conference the First Southeast Asia Regional Conference of Psychology: "Human well-being and Sustainable Development", 2, 70-77.

Nguyen, T. H. P. (2011a). Trauma in women suffering from infertility. Vietnam Journal of Family and Gender Studies, 1, 68-80.

Nguyen, T. H. P. (2011b). Social attitudes on infertility: Women's situation and response. Proceedings of International Conference: 20 years of Faculty of Sociology Achivements and Challenges, 350-358.

Öztürk, R., Bloom, T. L., Li, Y., \& Bullock, L. F. C. (2021). Stress, stigma, violence experiences and social support of us infertile women. Journal of Reproductive and Infant Psychology, 39, 205-217. https://doi.org/10.1080/02646838.2020.1754373

Patel, M. (2016). The socioeconomic impact of infertility on women in developing countries. Facts, Views \& Vision in ObGyn, 8, 59-61.

Pedro, A. (2015). Coping with infertility: an explorative study of South African women's experiences. Open Journal of Obstetrics and Gynecology, 5, 49-59. https://doi.org/10.4236/ojog.2015.51008

Peterson, B. D., Pirritano, M., Christensen, U., \& Schmidt, L. (2008). The impact of partner coping in couples experiencing infertility. Human Reproduction, 23, 1128-1137. https://doi.org/10.1093/ humrep/den067

Podolska, M. Z., \& Bidzan, M. (2011). Infertility as a psychological problem. Ginekologja Polska, 82, 44-49.

Rashidi, B., Hosseini, S., Beigi, P., Ghazizadeh, M., \& Farahani, M. N. (2011). Infertility stress: The role of coping strategies, personality trait, and social support. Journal of Family and Reproductive Health, 5, 101-108.

Roupa, Z., Polikandrioti, M., Sotiropoulou, P., Faros, E., Koulouri, A., Wozniak, G., \& Gourni, M. (2009). Causes of infertility in women at reproductive age. Health Science Journal, 3, 80-87.

Schmidt, L., Christensen, U., \& Holstein, B. E. (2005a). The social epidemiology of coping with infertility. Human Reproduction, 20, 1044-1052. https://doi. org/10.1093/humrep/deh687

Schmidt, L., Holstein, B. E., Christensen, U., \& Boivin, J. (2005b). Communication and coping as predictors of fertility problem stress: Cohort study of 816 participants who did not achieve a delivery after 12 months of fertility treatment. Human Reproduction, 20, 3248-3256. https://doi.org/10.1093/ humrep/dei193

Terry, D. J., \& Hynes, G. J. (1998). Adjustment to a low-control situation: Reexamining the role of coping responses. Journal of Personality and Social Psychology, 74, 1078-1092. https://doi.org/10.1037/ 0022-3514.74.4.1078

The Practice Committee of the American Society for Reproductive Medicine (2006). Aging and infertility in women. Fertility and Sterility, 86, S248-S252. https://doi.org/10.1016/j.fertnstert.2006.08.024
Infertility-related stress, social support, and coping of women 
Lam Q. Truong,

Thuy B. Luong,

Thu H. Tran,

Ngan H. Dang,

Lien H. Nguyen,

Trang T. Nguyen,

Phuong

T. H. Nguyen
Thoits, P. A. (1995). Stress, coping, and social support processes: Where are we? What next? Journal of Health and Social Behavior, 35, 53-79. https://doi. org/10.2307/2626957

Tran, H. T., Truong, Q. L., \& Nguyen, H. L. (2020). Need of parenthood and sexual stress among the infertiles. Journal of Psychology, Vietnam Academy of Social Sciences, 11, 68-83.

Truong, Q. L. (2020). Traumas in women suffering from infertility through a case study. Journal of Psychology, Vietnam Academy of Social Sciences, 3, 83-97.

Van den Broeck, U., Emery, M., Wischmann, T., \& Thorn, P. (2010). Counselling in infertility: Individual, couple and group interventions. Patient Education and Counseling, 81, 422-428. https://doi. org/10.1016/j.pec.2010.10.009

Verhaak, C. M., Smeenk, J. M. J., Evers, A. W. M., van Minnen, A., Kremer, J. A. M., \& Kraaimaat, F. W. (2005). Predicting emotional response to unsuccessful fertility treatment: a prospective study. Journal of Behavioral Medicine, 28, 181-190. https:// doi.org/10.1007/s10865-005-3667-0

Vo, T. M., Tran, Q. T. T., Le, C. V., Do, T. T., \& Le, T. M. (2019). Depression and associated factors among infertile women at Tu Du hospital, Vietnam: a crosssectional study. International Journal of Women's Health, 11, 343-351. https://doi.org/10.2147/ijwh. s205231

WHO (2012). Trends in maternal mortality: 1990 to 2010: WHO, UNICEF, UNFPA and the World Bank estimates. World Health Organization.

Wiersema, N. J., Drukker, A. J., Dung, M., Nhu, G., Nhu, N., \& Lambalk, C. B. (2006). Consequences of infertility in developing countries: Results of a questionnaire and interview survey in the South of Vietnam. Journal of Translational Medicine, 4, 54. https://doi.org/10.1186/1479-5876-4-54

Zegers-Hochschild, F., Adamson, G. D., de Mouzon, J., Ishihara, O., Mansour, R., Nygren, K., Sullivan, E., Vanderpoel, S., International Committee for Monitoring Assisted Reproductive Technology, \& World Health Organization (2009). International Committee for Monitoring Assisted Reproductive Technology (ICMART) and the World Health Organization (WHO) revised glossary of ART terminology, 2009. Fertility and Sterility, 92, 1520-1524. https:// doi.org/10.1016/j.fertnstert.2009.09.009

Zimet, G. D., Dahlem, N.W., Zimet, S. G., \& Farley, G. K. (1988). The Multidimensional Scale of Perceived Social Support. Journal of Personality Assessment, 52, 30-41. https://doi.org/10.1207/s15327752jpa5201_2 